Research Article

\title{
Prescription audit for evaluation of present prescribing trends in a rural tertiary care hospital in South India: an observational study
}

\author{
Nagashree B. N., Ravi Shankar Manchukonda*
}

Department of Pharmacology, Adichunchanagiri Institute of Medical Sciences, B G Nagar, Nagamangala Taluq, Mandya, Karnataka, India

\section{Received: 13 July 2016} Accepted: 09 August 2016

\section{*Correspondence to:}

Dr. Ravi Shankar Manchukonda, Email:ravipharmac@yahoo.com

Copyright: (C) the author(s), publisher and licensee Medip Academy. This is an openaccess article distributed under the terms of the Creative Commons Attribution NonCommercial License, which permits unrestricted noncommercial use, distribution, and reproduction in any medium, provided the original work is properly cited.

\begin{abstract}
Background: Prescription is a written order from the physician to pharmacist which contains name of the drug, its dose and its method of dispensing and advice over consuming it. The quality of life can be improved by enhancing the standards of the medical treatment at all levels of the health care delivery system. Prescription audit aims to provide precise information to a particular setting which enables rational policy decisions to be made. The present study was undertaken to find errors in current prescription practices in a tertiary care hospital situated in B G Nagara, Nagamangala, India.

Methods: An observational study in Adichunchanagiri Institute of Medical Sciences, B G Nagara, Nagamangala, India was conducted during October 2015. 113 prescriptions were analyzed. Information regarding the patient, doctor, drug and legibility of the prescription were obtained.

Results: Regarding patient details, name was present in all prescriptions with absence of height and weight in all prescriptions. Regarding prescriber details name, qualifications, address, phone number were not found in any prescriptions, but with $100 \%$ presence of signature. Regarding drug details generic name was found in $9.7 \%$, and dose and frequency were found in $96.45 \%$ and $95.5 \%$ respectively. $96.4 \%$ of the prescriptions were found to be legible.

Conclusions: Irrational prescribing is a global problem. The rationality of prescribing pattern is of utmost importance because bad prescribing habits including misuse, overuse and underuse of medicines can lead to unsafe treatment, exacerbation of the disease, health hazards, economic burden on the patients and wastage. Computerised prescription ordering eliminates some of the subjective features of prescribing. Thus, if the proper information is entered correctly in the electronic system, medication errors due to illegible handwriting, incorrect dose, incorrect medication for medical condition, and drug interactions can be reduced, because each prescription can be linked to high-quality drug databases that check that the information on the prescription is appropriate for the patient (e.g., age, weight, gender, condition, lab values, disease being treated, concurrent medications) and that known warnings and potential problems are brought to the attention of the physician, pharmacist and patient.
\end{abstract}

Keywords: Prescription audit, Errors in prescription, Legibility, E- prescription

\section{INTRODUCTION}

The quality of life can be improved by enhancing the standards of the medical treatment at all levels of the health care delivery system. ${ }^{1}$

Prescription is a written order from the physician to pharmacist which contains name of the drug, its dose and its method of dispensing and advice over consuming it. ${ }^{2}$
Irrational prescribing is a global problem. The rationality of prescribing pattern is of utmost importance because bad prescribing habits including misuse, overuse and underuse of medicines can lead to unsafe treatment, exacerbation of the disease, health hazards, economic burden on the patients and wastage. ${ }^{3}$

These prescription errors may lead to adverse drug events. The study done to assess adverse drug events by Bates et al. found $28 \%$ of adverse drug events to be 
preventable in their study and concluded that $56 \%$ of those preventable adverse events occurred at the stage ofordering. ${ }^{4}$

The prescription consists of the superscription, the inscription, the subscription, the signa, and the name and signature of the prescriber, all contained on a single form. The superscription includes the date the prescription order is written; the name, address, weight, and age of the patient; and the $\mathrm{R}_{\mathrm{x}}$ (Take). The body of the prescription, or inscription, contains the name and amount or strength of the drug to be dispensed, or the name and strength of each ingredient to be compounded. The subscription is the instruction to the pharmacist, usually consisting of a short sentence such as: "make a solution," "mix and place into 30 capsules," or "dispense 30 tablets." The signa of "Sig" is the instruction to the patient as to how to take the prescription, interpreted and transposed onto the prescription label by the pharmacist. ${ }^{5}$

From the wrong drug prescribed to the wrong dosage or administration schedule advised, dispensed or administered, the impact of medication misadventures is a costly problem. Errors of these sorts occur because human beings are involved, and such errors can be prevented only by systems that make it difficult to do the wrong thing. ${ }^{5}$

Efforts to reduce the number of drug-related adverse events due to misinterpretation, medical error, inappropriate prescribing, or patient noncompliance could result in substantial savings and, more important, improved patient health. ${ }^{6}$

Prescription audit aims to provide precise information to a particular setting which enables rational policy decisions to be made.

Hence the present study has been undertaken to know the current prescription trend and its adherence to standard prescribing pattern.

\section{METHODS}

An observational cross sectional study was conducted at the tertiary care hospital located in B G Nagara, Mandya, India during October 2015. The study was carried out for a period of 15 days, in one of our out- patient departments of our hospital Adichunchanagiri hospital and research centre, BG Nagara, Karnataka. The data was entered into a proforma. The proforma had four parts. Main information was regarding patient, doctor, drug and legibility.

Patient information that was sought included the name, age, sex, address, height and weight with date of prescription. Doctor information included name, seal, qualification, designation, complete address, phone number, signature and registration number of the doctor. Drug information contained brand or generic name, dose, frequency and route of administration, quantity, duration, instructions and advice to patient for follow up. Lastly legibility of prescription was analysed. The anonymity of the patients and doctors were strictly maintained. The ethical approval was obtained from institutional ethics committee. The WHO guidelines and indicators for prescription writing has been taken as standard while making an assessment of the results. ${ }^{[8][9]}$ A total of 113prescriptions were analyzed. The results were expressed in percentages.

\section{RESULTS}

Table 1: Analysis of patient information on the prescription.

\begin{tabular}{|lllll|}
\hline Patient & Present & \multicolumn{3}{c|}{ Absent } \\
Particulars & Number & $\mathbf{\%}$ & Number & \% \\
\hline Name & 113 & 100 & - & - \\
\hline Age & 59 & 52.2 & 54 & 47.8 \\
\hline Sex & 21 & 18.5 & 92 & 81.5 \\
\hline Address & 11 & 9.7 & 102 & 90.3 \\
\hline Height & - & - & 113 & 100 \\
\hline Weight & - & - & 113 & 100 \\
\hline $\begin{array}{l}\text { Date of } \\
\text { prescription }\end{array}$ & 111 & 98.2 & 2 & 1.8 \\
\hline
\end{tabular}

Table 2: Analysis of Doctor's information on the prescription.

\begin{tabular}{|lllll|}
\hline $\begin{array}{l}\text { Doctor } \\
\text { particulars }\end{array}$ & Present & \multicolumn{3}{c|}{ Absent } \\
\hline Name & - & - & 113 & 100 \\
\hline Qualification & - & - & 113 & 100 \\
\hline Designation & - & - & 113 & 100 \\
\hline Address & - & - & 113 & 100 \\
\hline Phone number & - & - & 113 & 100 \\
\hline signature & 113 & 100 & - & - \\
\hline $\begin{array}{l}\text { Registration } \\
\text { number }\end{array}$ & - & - & 113 & 100 \\
\hline
\end{tabular}

Table 3: Analysis of drug information on prescription.

\begin{tabular}{|lllll|}
\hline $\begin{array}{l}\text { Drug } \\
\text { Particulars }\end{array}$ & Number & \% & Number & \% \\
\hline Brand name & 102 & 90.3 & 11 & 9.7 \\
\hline Generic name & 11 & 9.7 & 102 & 90.3 \\
\hline Dose & 109 & 96.4 & 4 & 3.6 \\
\hline Frequency & 108 & 95.5 & 5 & 4.5 \\
\hline $\begin{array}{l}\text { Medication } \\
\text { form }\end{array}$ & 101 & 89.3 & 12 & 10.7 \\
\hline Quantity & 94 & 83.2 & 19 & 16.8 \\
\hline Duration & 97 & 85.8 & 16 & 14.2 \\
\hline Instructions & 92 & 81.4 & 21 & 18.6 \\
\hline $\begin{array}{l}\text { Advise for } \\
\text { follow-up }\end{array}$ & 66 & 58.4 & 47 & 41.6 \\
\hline
\end{tabular}


Table 4: Analysis of legibility of prescription.

\begin{tabular}{|lll|}
\hline Legibility & Number & $\%$ \\
\hline Legible & 109 & 96.4 \\
\hline Illegible & 4 & 3.6 \\
\hline
\end{tabular}

\section{DISCUSSION}

In healthcare, implementation of guidelines has generally been reported as fragmented and inconsistent and still remains a significant challenge for various healthcare organizations. ${ }^{10}$

Medical audit is the critical assessment of medical and healthcare related system with a view to bring about necessary improvement in the same. Prescription audit is a part of Medical audit and is seen as one approach to improve the quality of patient care. ${ }^{11}$

In our study 113 prescriptions were analyzed, regarding patient details, name of the patient were present in all the prescriptions when compared to findings of Irshaid et al who found $94.6 \%$ of prescription with name. But age and sex of the patient was mentioned only in $52.2 \%$ and $18.5 \%$ of the prescriptions in our study (Table1). This was very much lower compared to $77.2 \%$ and $51.3 \%$ in the study done by Irshaid et al. ${ }^{[12]}$. Address of the patient was present only in $9.7 \%$, and the absence of height and weight is indicator of poor prescription trend. Date of the prescription was present in $98.2 \%$.

There was huge lack of the information regarding doctor/prescriber (Table 2). None of the prescriptions had name, qualification, designation, registration number, address and telephone number of the doctor which have same results with one of study in Maharashtra, India. ${ }^{13}$ However signature was present in $100 \%$ when compared to $33.3 \%$ in a study conducted by Laura et al. ${ }^{14}$

Regarding drug details, only $9.7 \%$ had generic name (Table 3 ) when compared to $15 \%$ in a study conducted by Anuja A pandey et al. and study carried out at Jimma Hospital, south west Ethiopia had $75.2 \%$ prescriptions with generic name. ${ }^{15,16}$ Dose, frequency, medication form were present in 96.4 , 95.5and $89.3 \%$ respectively, with $81.4 \%$ of prescriptions with instructions.

Illegible handwriting can lead to medication error which can cause fatal consequences. ${ }^{17}$ Our study found $96.4 \%$ of prescriptions to be legible (Table 4), when compared to $86.8 \%$ in a study conducted at Ambala, Haryana. ${ }^{18}$ Heavy workload is one of the common reasons offered by the doctors for poor handwriting and educational interventions were found effective to address the problem. $^{19}$

A prescription is an instruction from a prescriber to a dispenser. The prescriber is not always a doctor but can also be a paramedical worker, such as a medical assistant, a midwife or a nurse. The dispenser is not always a pharmacist but can be a pharmacy technician, an assistant or a nurse. Every country has its own standards for the minimum information required for a prescription, and its own laws and regulations to define which drugs require a prescription and who is entitled to write it. ${ }^{8}$

The era of e-prescribing has begun. Its implementation is still expensive, but the subsequent benefits to patients and savings in personnel costs, along with its integration with electronic medical records, drug inventory control, and billing, point to the wide use of e-prescribing in the future. 5

Computerised prescription ordering eliminates some of the subjective features of prescribing. Thus, if the proper information is entered correctly in the electronic system, medication errors due to illegible handwriting, incorrect dose, incorrect medication for medical condition, and drug interactions can be reduced, because each prescription can be linked to high-quality drug databases that check that the information on the prescription is appropriate for the patient (e.g., age, weight, gender, condition, lab values, disease being treated, concurrent medications) and that known warnings and potential problems are brought to the attention of the physician, pharmacist and patient. Such systems may not be used as a substitute for personal attention to the individual patient by healthcare workers but, rather, as an adjunct measure that ensures safe, high-quality, efficient care.

Efforts to reduce the number of drug-related adverse events due to misinterpretation, medical error, inappropriate prescribing, or patient noncompliance could result in substantial savings and, more important, improved patient health. ${ }^{6}$

By examining aspects of prescription writing that can cause errors and by modifying prescribing habits accordingly, the physician can improve the chance that the patient will receive the correct treatment, whether in a hospital or an outpatient setting. ${ }^{6}$

All orders should be written using metric measurements. To avoid confusion, Arabic (decimal) numerals are preferable to Roman numerals, and in some instances, it is preferable for numbers to be spelled out. When writing decimal fraction numbers, health care professionals always should use leading zeros $(0.125 \mathrm{mg}$, not $.125 \mathrm{mg})$, never used trailing zeros ( $5 \mathrm{mg}$, not $5.0 \mathrm{mg}$ ), and decimal points should be indicated carefully, as these often are reported as source of dosage errors. ${ }^{6}$

Errors in the management of drug therapy result in a large number of preventable injuries suffered by patients. ${ }^{20}$

\section{CONCLUSION}

Irrational prescribing is a global problem. The rationality of prescribing pattern is of utmost importance because bad prescribing habits including misuse, overuse and 
underuse of medicines can lead to unsafe treatment, exacerbation of the disease, health hazards, economic burden on the patients and wastage. Efforts to reduce the number of drug-related adverse events due to misinterpretation, medical error, inappropriate prescribing, or patient noncompliance could result in substantial savings and, more important, improved patient health.

Computerised prescription ordering eliminates some of the subjective features of prescribing. Thus, if the proper information is entered correctly in the electronic system, medication errors due to illegible handwriting, incorrect dose, incorrect medication for medical condition, and drug interactions can be reduced, because each prescription can be linked to high-quality drug databases that check that the information on the prescription is appropriate for the patient (e.g., age, weight, gender, condition, lab values, disease being treated, concurrent medications) and that known warnings and potential problems are brought to the attention of the physician, pharmacist and patient. Such systems may not be used as a substitute for personal attention to the individual patient by healthcare workers but, rather, as an adjunct measure that ensures safe, high-quality, efficient care.

Funding: No funding sources

Conflict of interest: None declared

Ethical approval: The study was approved by the Institutional Ethics Committee

\section{REFERENCES}

1. Curtis P. Medical audit in general practice. J R Coll Gen Pract. 1974;24(146):607-11.

2. Tripathi KD. Text book of pharmacology. Jaypee Brothers; New Delhi. 2003:3.

3. Hogerzeil HV. Promoting rational prescribing: an international perspective. $\mathrm{Br} \mathrm{J}$ Clin Pharmacol. 1995;39:1-6.

4. Bates DW, Cullen D, Laird N, Petersen LA, Small $\mathrm{SD}$, Servi D, et al. Incidence of adverse drug events and potential adverse drug events: Implications for prevention. JAMA. 1995;274:29-34.

5. Buxton LO. Principles of prescription order writing and patient compliance. In: Brunton L Laurence, Chabner A Bruce, Knollmann C Bjorn, Editors. Goodman and Gilman's The Pharmacological Basis of Therapeutics. 12th Ed. New Delhi: Mc Graw Hill. 2011;1879-89.

6. Lauralea E, M Dan R. Principles of prescription order writing and patient compliance. In: Joel G. Hardman, Lee E. Limbird, Editors. Goodman and
Gilman's The Pharmacological Basis of Therapeutics. 10th Ed. New Delhi: Mc Graw Hill. 2001;1903-15.

7. Patterson HR, Coll JR. The problems of audit and research. Gen. Pract. 1986;36:196-200.

8. De Vries TP. Guide to good prescribing: a practical manual Genev. World Health Organization. 1995;5.

9. Essential medicines and health care products information portal A World health organization resource available at http://apps.who.int/medicinedocs/en/d/Js2289e/3.1.h tml. Accessed on 13-7-2016.

10. Burnier M. Blood pressure control and the implementation of guidelines in clinical practice: can we fill the gap? J Hypertens. 2002;20(7):1251-3.

11. Walshe K. Introduction. Evaluating clinical audit; past lessons, future directions. London: The Royal Society of Medicine Press. 1995.

12. Irshaid YM, Homrany MA, Hamdi AA. AdjeponYamoah KK, Mahfouz AA. Compliance with good practice in prescription writing at outpatient clinics in Saudi Arabia. Eastern Mediterranean Health Journal. 2005;11(5-6):922-8.

13. Phalke DV. Prescription writing practices in a rural tertiary care hospital in Western Maharashtra, India: Australas Med J. 2011;4(1):4-8.

14. Laura C, Angela P, Luca A, Carla L, Rosanna QT, Maria TG. Errors and omissions in hospital prescriptions: a survey of prescription writing in a hospital. BMC Clin Pharmacol. 2009;9.

15. Anuja PA, Subhash TB, Prakash BR. Prescription Analysis of Pediatric Outpatient Practice in Nagpur City. Indian J Community Med. 2010;35(1):70-3.

16. Abdulahi M, Shiferaw T. Pattern of prescription in Jimma Hosptial. Ethiop J Health Dev. 1997;11(3):263-7.

17. Boehringer PA, Rylander J, Dizon DT, Peterson MW. Improving the Quality of the Order writing. Process for Inpatient Orders in a Teaching Hospital. Q Manage Health Care. 2007;16(3):215-8.

18. Kaur B, Walia R. Prescription audit for evaluation of prescribing pattern of the doctors for rational drug therapy in a tertiary care hospital. Journal of Drug Delivery \& Therapeutics. 2013;3(5):77-80.

19. Obehi AA, Ambrose IO. Prescription writing in public and private hospitals in Benin City, Nigeria: the effects of an educational intervention. Can J Clin Pharmacol. 2008;15(2):295-305.

20. Classen DC, Pestotnik SL, Evans RS, Burke JP. Computerized surveillance of adverse drug events in hospital patients. JAMA. 1991;266:2847-51.

Cite this article as: Nagashree BN, Manchukonda RS. Prescription audit for evaluation of present prescribing trends in a rural tertiary care hospital in South India: an observational study. Int J Basic Clin Pharmacol 2016;5:2094-7. 